\title{
Single-Walled-Carbon-Nanotube-Modified Pyrolytic Graphite Electrode Used as a Simple Sensor for the Determination of Salbutamol in Urine
}

\author{
Rajendra N. Goyal, Sunita Bishnoi, and Bharati Agrawal \\ Department of Chemistry, Indian Institute of Technology Roorkee, Roorkee 247667, India \\ Correspondence should be addressed to Rajendra N. Goyal, rngcyfcy@iitr.ernet.in
}

Received 2 December 2010; Accepted 23 December 2010

Academic Editor: Bengi Uslu

Copyright $\odot 2011$ Rajendra N. Goyal et al. This is an open access article distributed under the Creative Commons Attribution License, which permits unrestricted use, distribution, and reproduction in any medium, provided the original work is properly cited.

\begin{abstract}
A fast and sensitive voltammetric method has been proposed for the determination of salbutamol at single-walled-carbonnanotube-modified edge-plane pyrolytic graphite electrode (SWNT/EPPGE) in human urine. The electrochemical response of salbutamol was determined by square wave voltammetry (SWV) in phosphate buffer solution (PBS) at physiological pH 7.2. The modified electrode showed improved voltammetric response towards the oxidation of salbutamol, and a well-defined anodic peak was observed at $\sim 600 \mathrm{mV}$ with enhanced peak current in comparison to the bare electrode. Linear calibration plot using SWNT/EPPGE was obtained in the concentration range of 50 to $2500 \mathrm{ngml}^{-1}$ with sensitivity and detection limit of $2.15 \mathrm{nA} / \mathrm{ngml}^{-1}$ and $4.31 \mathrm{ngml}^{-1}$, respectively. The developed method has been successfully applied for the determination of salbutamol in commercial preparations and human body fluids. Fast analysis of salbutamol in human urine makes the proposed method of great interest for doping control purposes at the site of competitive games.
\end{abstract}

\section{Introduction}

$\beta_{2}$-agonists are effective bronchodilators and normally used in symptomatic treatment of asthma and chronic bronchitis [1-3]. Salbutamol ( $\alpha^{1}-[($ tert-butylamino) methyl]-4hydroxy-m-xylene- $\alpha, \alpha^{\prime}$-diol) (Scheme 1 ) is a direct-acting $\beta_{2}$-agonist with beta-adrenergic activity employed as bronchodilator for the treatment of asthmatic disorders and chronic obstructive pulmonary diseases $[4,5]$. It is also used to reduce premature labor in pregnancy [6]. Salbutamol is commonly administrated as pressurized metered dose inhaler and nebulized aerosol [7]. Salbutamol has been pharmacologically proven to be able to increase muscle protein, reduce total body fat, and promote muscle growth, therefore, it is highly abused by athletes to improve muscular strength and in turn improve their performance in sports [8-10]. The list of prohibited substances in sports published by the World Anti-Doping Agency (WADA) specifies that salbutamol can be used only by inhalation. Administration of salbutamol by oral or parenteral route and very large inhaled dose are forbidden due to strong adrenergic stimulation. The threshold concentration of $1000 \mathrm{ng} / \mathrm{mL}$ has been established to suspect for oral administration of salbutamol by the WADA rules $[11,12]$. A concentration of salbutamol greater than $1000 \mathrm{ng} / \mathrm{mL}$ is considered as an adverse analytical finding of anabolic agent and constitutes a doping violation [13]. In view of the extensive use and misuse of salbutamol in sports, it has been mandatory to analyze salbutamol concentration in pharmaceutical formulations as well as in biological fluids.

Several techniques have been explored for the determination of salbutamol to monitor the therapeutic use as well as to control illegal use. This includes high-performance liquid chromatography [14], capillary electrophoresis with UV detection [15], flow-injection analysis using spectrophotometric method [16], solid-phase extraction method [17], conductometric method [18], and electrogenerated chemiluminescence detection [19]. Although spectrophotometry and chromatography are the most commonly employed techniques, but these involve many derivatization steps and 
<smiles>CC(C)(C)NCC(O)c1ccc(O)c(CO)c1</smiles>

Scheme 1

an effective extraction purification approach prior to final analysis which is very time consuming and the demand of expensive and heavy instrumentation. The voltammetric methods have been proven to be advantageous alternative way due to their simplicity, high sensitivity, and rapidness $[20,21]$. Hence, the determination of salbutamol at variety of electrodes has been attempted [22-27]. In many of these investigations, biological samples particularly urine have not been analyzed; hence, their usefulness could not be ascertained. In several others, the detection limit was much higher than expected to be present in blood plasma or urine. In the last few years our laboratory has been also trying to develop an efficient sensor for the determination of salbutamol [23]; however, at nanogold-modified electrode, a detection limit of $0.30 \mu \mathrm{M}$ is achieved. As the preparation of nanogold electrode is tedious and the size of nanoparticles depends on time for which ITO sheet is dipped in the solution for crystal growth [28], pyrolytic graphite modified with carbon nanotubes is used in the present studies. The aim of the present work is to develop a fast and sensitive voltammetric sensor for the direct determination of salbutamol in human body fluids particularly urine as it can easily detect the cases of doping at the site of competitive games. The EPPGE has been proved to be an effective substrate for detecting lower concentration of biomolecules and drugs in comparison to other conventional electrodes [29, 30]. Carbon nanotubes are expected to increase electrochemical performance of electrodes due to their excellent electrical conductivity, nanometer size, and good chemical stability [31-35]. Therefore, the studies have been performed at SWNT/EPPGE. Square wave voltammetry is one of the widely used techniques due to its higher sensitivity, simplicity, and lower limit of detection for drugs and biomolecules [36, 37]; hence, it has been utilized for the sensitive sensing of salbutamol in body fluids and pharmaceutical preparations to monitor clinical and doping cases.

\section{Experimental}

2.1. Instrumentation. The voltammetric studies were carried out using BAS (Bioanalytical System, West Lafayette, USA) CV-50W voltammetric analyzer. The voltammetric cell used was a single compartment glass cell containing SWNT/EPPGE as working electrode, a platinum wire as counter electrode, and $\mathrm{Ag} / \mathrm{AgCl}(3 \mathrm{M} \mathrm{NaCl})$ as reference electrode (model BAS MF-2052 RB-5B). The edge-plane pyrolytic graphite piece was obtained from Pfizer Inc., New York, USA, and the electrode was prepared as reported earlier in literature [38]. The $\mathrm{pH}$ of the buffer solutions was measured using digital $\mathrm{pH}$ meter (Model CP-901), Century India Ltd. All potential are reported with respect to $\mathrm{Ag} / \mathrm{AgCl}$ reference electrode at an ambient temperature of $27 \pm 2^{\circ} \mathrm{C}$.

2.2. Chemicals and Reagents. Salbutamol sulphate in powdered form was obtained as a gift sample from Vamsi labs Ltd., Maharashtra, India. SWNTs of purity $>98 \%$ were purchased from Bucky USA, Houston, Tex, USA. Salbutamol-containing tablets of different companies were purchased from local market. Phosphate buffer solutions (1 M) were prepared according to the method of Christian and Purdy [39]. All chemicals used were of analytical grade and were purchased from Merck. Double-distilled water was used throughout the experiments.

2.3. Preparation of $S W N T / E P P G E$. Prior to modification, the surface of EPPGE was rubbed on an emery paper followed by cleaning it with double-distilled water and soft touching with tissue paper. Firstly, different concentrations of nanotubes in $\mathrm{N}, \mathrm{N}$-dimethylformamide (DMF) were prepared. Then, $0.5 \mathrm{mg} / \mathrm{mL}$ was selected as optimum based on the optimum current response of fixed concentration of salbutamol. A $0.5 \mathrm{mg} / \mathrm{mL}$ suspension of SWNT was prepared by dispersing $0.5 \mathrm{mg}$ SWNT in $1.0 \mathrm{~mL}$ DMF by ultrasonic agitation. A known volume $(40 \mu \mathrm{L})$ of this suspension was coated onto the surface of the bare EPPGE, and the solvent was allowed to evaporate at room temperature. The modified electrode was now ready for use. The surface morphology of the bare and modified electrodes was characterized by recording FE-SEM using Quanta 200 FE-SEM instrument. A comparison of FESEM images of the bare and SWNT-modified electrodes is presented in Figure 1 and clearly indicates the deposition of SWNT on the surface of the electrode. The surface of bare pyrolytic graphite appears to be rough, whereas in the case of modified electrode the deposition of SWNT with some agglomeration is observed in FE-SEM.

2.4. Analytical Procedure. Stock solution of salbutamol $(1 \mathrm{mM})$ was prepared by dissolving the required amount of compound in double-distilled water. A known amount of stock solution was added to $2.0 \mathrm{~mL}$ phosphate buffer, and the total volume of $4.0 \mathrm{~mL}$ was obtained with double-distilled water. Square wave voltammograms were then recorded at the optimized parameters: initial $E: 0 \mathrm{mV}$, final $E: 1200 \mathrm{mV}$, square wave frequency $(f): 15 \mathrm{~Hz}$, square wave amplitude $\left(E_{\mathrm{sW}}\right): 20 \mathrm{mV}$, and step $E: 4 \mathrm{mV}$. Urine sample of an asthma patient (male, 30 years, $45 \mathrm{~kg}$ ) undergoing treatment with salbutamol from 8 months and blood plasma samples of healthy volunteers (female, 25 years, $50 \mathrm{~kg}$; male, 30 years, $55 \mathrm{~kg}$ ) were obtained from the Institute Hospital of IIT Roorkee. Blood sample was ultracentrifuged at a speed of $1000 \mathrm{rpm}$ for $5 \mathrm{~min}$, and supernatant blood plasma was used for the determination of salbutamol. Urine and blood samples were diluted 2 and 4 times, respectively, with phosphate buffer solution of $\mathrm{pH} 7.2$ prior to analysis. 


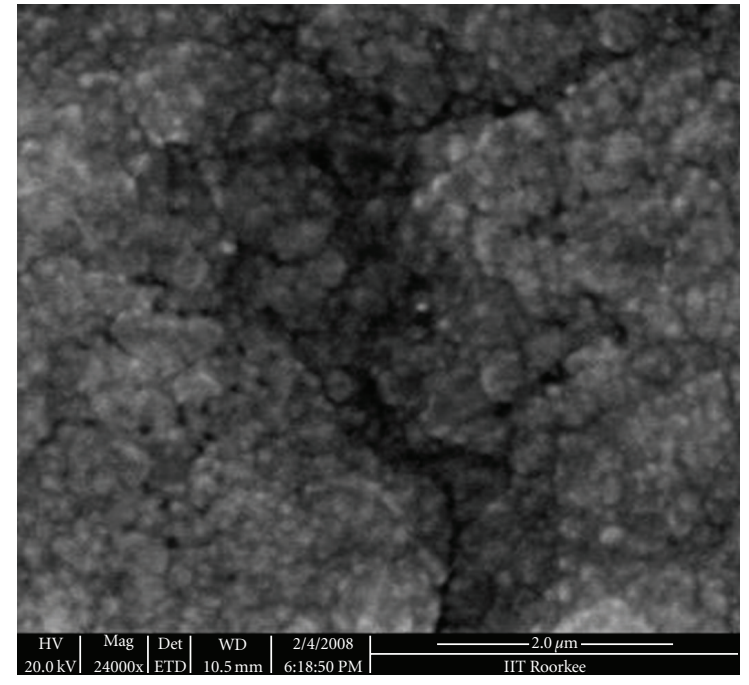

(a)

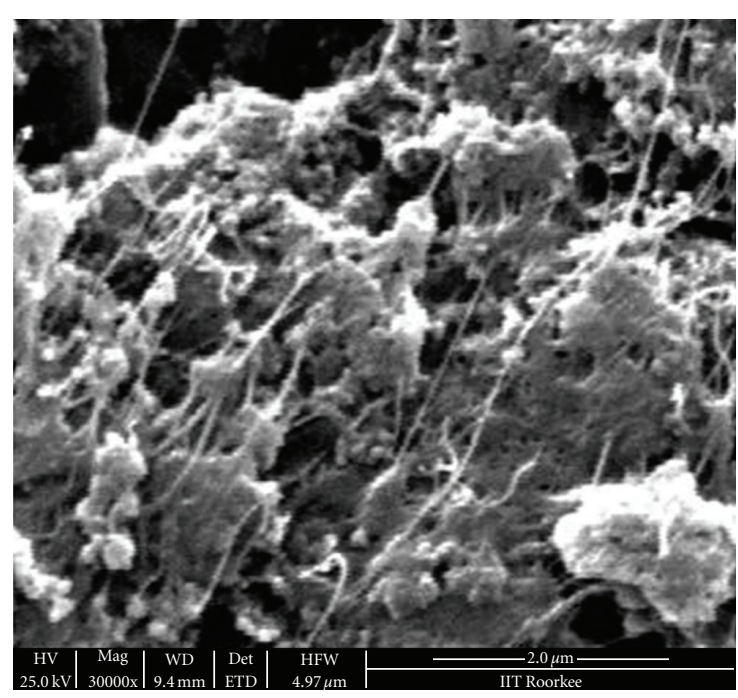

(b)

FIGURE 1: Typical FE-SEM images of (a) bare and (b) SWNT/EPPGE.

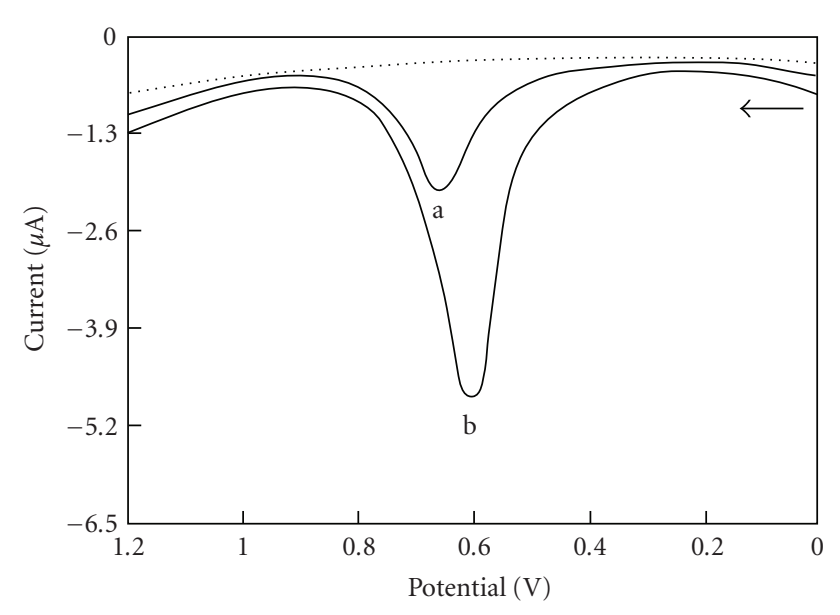

FIGURE 2: Comparison of square wave voltammograms for $2000 \mathrm{ng} / \mathrm{mL}$ of salbutamol at bare electrode (peak a) and SWNTmodified electrode (peak b) at pH 7.2 and background PBS (1 M) at SWNT/EPPGE (...).

\section{Results and Discussion}

3.1. Comparison of Bare and Modified Electrode. Electrochemical properties of salbutamol were demonstrated by using square wave voltammetry at bare and SWNT-modified EPPGE in phosphate buffer solution of $\mathrm{pH}$ 7.2. Figure 2 clearly indicates that on scanning the potential from 0 to $1200 \mathrm{mV}$ oxidation peak was noticed at $\sim 660 \mathrm{mV}$ (peak a) using the bare electrode while for the modified electrode the oxidation peak appeared at $\sim 600 \mathrm{mV}$ (peak b) having marked increment in current value as compared to the bare electrode for $2000 \mathrm{ng} / \mathrm{mL}$ salbutamol. The significant improvement in peak current with decreasing potential clearly demonstrates that single-walled carbon nanotubes act as an efficient electron mediator for the oxidation of salbutamol. The edge-plane-like defects which are present at the open ends of nanotubes and the embedded metal impurities in CNT samples are important reasons responsible for electrocatalytic properties of nanotubes [40, 41]. The modified electrode acts as a better substrate for voltammetric oxidation of salbutamol; therefore, further detailed studies were carried out at SWNT-modified EPPGE.

\subsection{Electrochemical Behavior of Salbutamol}

3.2.1. Cyclic Voltammetry. Cyclic voltammetry is one of the most widely used techniques which provide considerable information about the electrode reaction. Electrochemical response of salbutamol was determined by recording the cyclic voltammogram of $5000 \mathrm{ng} / \mathrm{mL}$ salbutamol at SWNTmodified EPPGE in phosphate buffer of $\mathrm{pH} 7.2$ at scan rate of $20 \mathrm{mV} / \mathrm{s}$. Figure 3 shows that a well-defined anodic peak is observed with peak potential of $\sim 657 \mathrm{mV}$ for salbutamol oxidation at SWNT/EPPGE. The absence of any peak in the reverse sweep clearly indicates that salbutamol was oxidized irreversibly at SWNT/EPPGE. Then, to analyze the nature of electrode reaction, cyclic voltammograms of $2000 \mathrm{ng} / \mathrm{mL}$ salbutamol were recorded at different scan rates in the range from 20 to $330 \mathrm{mV} / \mathrm{s}$ as shown in inset of Figure 3 . It was found that peak current increases linearly with the increase in scan rate $(v)$, and the plot of $i_{p}$ versus $v^{1 / 2}$ clearly indicated that the reaction occurring at the surface of modified electrode is governed by the diffusion process $[42,43]$. The dependence of peak current on scan rate can be expressed by the following relation:

$$
i_{p}(\mu A)=1.273 v^{1 / 2}-3.223,
$$

where $v$ is scan rate $(\mathrm{mV} / \mathrm{s})$ having a correlation coefficient of 0.997 , where $v$ is sweep rate in $\mathrm{mV} / \mathrm{s}$. Since SWV is more 


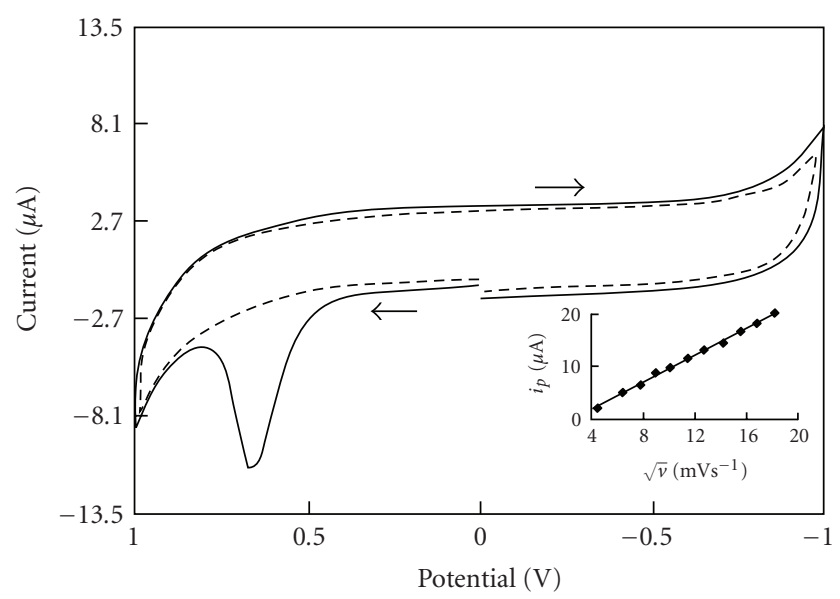

Figure 3: Cyclic voltammogram for $5000 \mathrm{ng} / \mathrm{mL}$ of salbutamol at SWNT-modified EPPGE (-) and background PBS at SWNTmodified EPPGE (- - ) at pH 7.2 and scan rate of $20 \mathrm{mV} / \mathrm{S}$. Inset: Effect of scan rate $(v)$ on peak current $\left(i_{p}\right)$ of salbutamol.

sensitive than other voltammetric techniques and has the advantage of suppressing the background current; hence, further studies for the determination of salbutamol in real samples were performed by square wave voltammetry.

3.2.2. Effect of $p H$. The $\mathrm{pH}$ of the supporting electrolyte is one of the variables that strongly affect the redox reaction of analytes. Hence, it is usually important to investigate the effect of $\mathrm{pH}$ on electrochemical system. In order to optimize $\mathrm{pH}$, the effect of $\mathrm{pH}$ on the oxidation of salbutamol was studied in the range of 2.3 to 9.9 using SWNT/EPPGE. The peak potential $\left(E_{p}\right)$ of salbutamol was found to shift towards the less positive potential with the increase in $\mathrm{pH}$ as shown in Figure 4(a). The linear dependence of peak potential on $\mathrm{pH}$ can be expressed by the following relations:

$$
\begin{gathered}
E_{p}(\mathrm{mV}) \text { versus } \frac{\mathrm{Ag}}{\mathrm{AgCl}}=980.9-51.52 \mathrm{pH} \quad \text { at } \frac{\mathrm{SWNT}}{\mathrm{EPPGE}}, \\
E_{p}(\mathrm{mV}) \text { versus } \frac{\mathrm{Ag}}{\mathrm{AgCl}}=1041.1-52.05 \mathrm{pH} \quad \text { at bare EPPGE, }
\end{gathered}
$$

having correlation coefficients of 0.995 and 0.992 , respectively. The observed slope of $\sim 52 \mathrm{mV} / \mathrm{pH}$ clearly indicates that an equal number of electrons and protons are involved in the electrode reaction [44]. It was found that at $\mathrm{pH}$ 6.0 peak current was comparatively higher than at $\mathrm{pH} 7.0$ for salbutamol solution; however, the study was performed in neutral media ( $\mathrm{pH} 7.20$ ) owing to the fact that the $\mathrm{pH}$ of human body fluids is almost equal to 7.00 and the determination of salbutamol in human body fluids was the main aim of proposed work.

\subsubsection{Study of the Linear Range, Sensitivity, and Detection} Limit. Square wave voltammograms of different concentration of salbutamol were recorded in order to plot calibration curves using bare and modified electrodes. A systematic increase in peak current is observed with an increase in concentration of salbutamol at electrodes surface. The peak current versus concentration plots presents a good linearity for bare and modified electrodes in the concentration range of 500-2500 ng/mL and 50-2500 ng/mL, respectively, as depicted in Figure 4(b). Linear relations between peak current and concentration of salbutamol can be expressed at both electrodes by the following equations:

$$
\begin{gathered}
i_{p}(\mathrm{nA})=2.147 C+0.445 \text { at } \frac{\text { SWNT }}{\text { EPPGE }} \\
i_{p}(\mathrm{nA})=0.830 C+2.125 \text { at bare EPPGE, }
\end{gathered}
$$

where $C$ is the concentration $(\mathrm{ng} / \mathrm{mL})$ of salbutamol having correlation coefficients of 0.996 and 0.995 , respectively. Figure 5 illustrates a series of square wave voltammograms obtained for salbutamol at different concentrations in $1 \mathrm{M}$ phosphate buffer solution of pH 7.2 using SWNT/EPPGE. The detection limit for modified electrodes was calculated by using the formula $3 \sigma / b$, where $\sigma$ is the standard deviation and $b$ is the slope of calibration curve, and was found to be $4.31 \mathrm{ng} / \mathrm{mL}$.

3.2.4. Stability and Reproducibility of SWNT/EPPGE. Reproducibility and stability are two important parameters of an electrode for the selective and sensitive quantitative determination. The stability of the modified electrode was examined by measuring the current response at fixed concentration of salbutamol over a period of 15 days. The electrode was used daily and stored in air. The experimental results show that the current intraday responses deviate by $1.28 \%$ and interday responses by $1.90 \%$, suggesting thereby that SWNT-modified EPPGE possesses good stability for the determination of salbutamol.

The reproducibility of modified electrode was evaluated by the repetitive measurements $(n=6)$ of salbutamol at a fixed concentration of $10 \mu \mathrm{M}$. The corresponding relative standard deviation of $0.4 \%$ confirms that results are satisfactorily reproducible. In order to examine intraday (repeatability) and interday (reproducibility) response, SWVs were recorded for a fixed concentration of salbutamol $(10 \mu \mathrm{M})$ using SWNT/EPPGE. The experimental results show that the current intraday responses deviate by $1.94 \%$ and interday responses by $2.40 \%$, suggesting thereby that SWNT/EPPGE possesses adequate reproducibility for the determination of salbutamol. Intra-electrode reproducibility is also an important parameter; hence, to examine electrode-to-electrode variation response, four pyrolytic graphite electrodes $(1 \times$ $1 \times 3 \mathrm{~mm}^{2}$ ) are casted with $40 \mu \mathrm{L}$ of SWNT suspension. It was observed that these electrodes show a variation of $\pm 2.9 \%$ in peak current of $10 \mu \mathrm{M}$ salbutamol. Thus, it is concluded that the electrode-to-electrode variation is nonsignificant. Thus, the SWNT-modified EPPGE exhibits a good reproducibility and stability for the determination of salbutamol, and therefore the proposed sensor is also recommended for the determination of similar drugs and biomolecules with good sensitivity and low detection limit. 


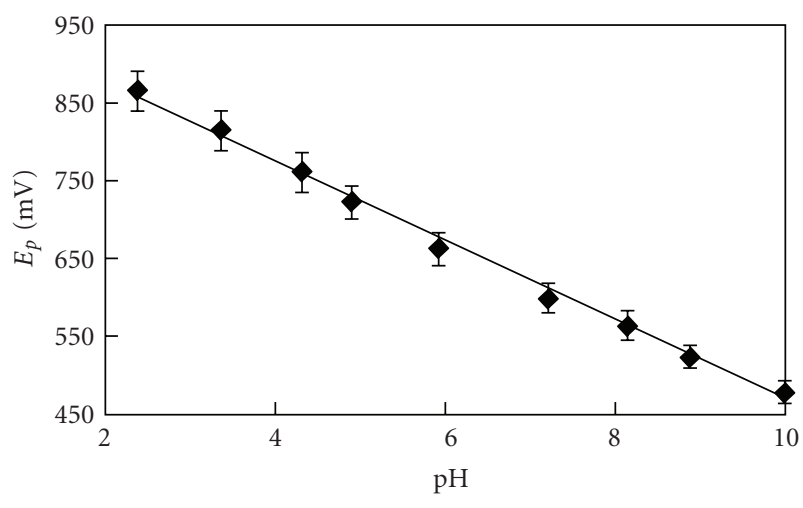

(a)

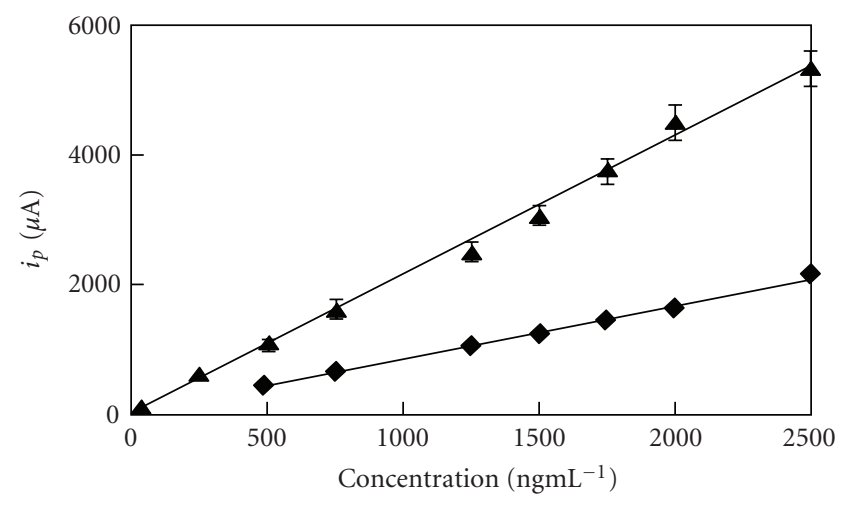

(b)

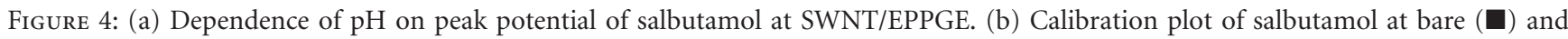
SWNT-modified EPPGE $(\boldsymbol{\Delta})$ at $\mathrm{pH}$ 7.2.

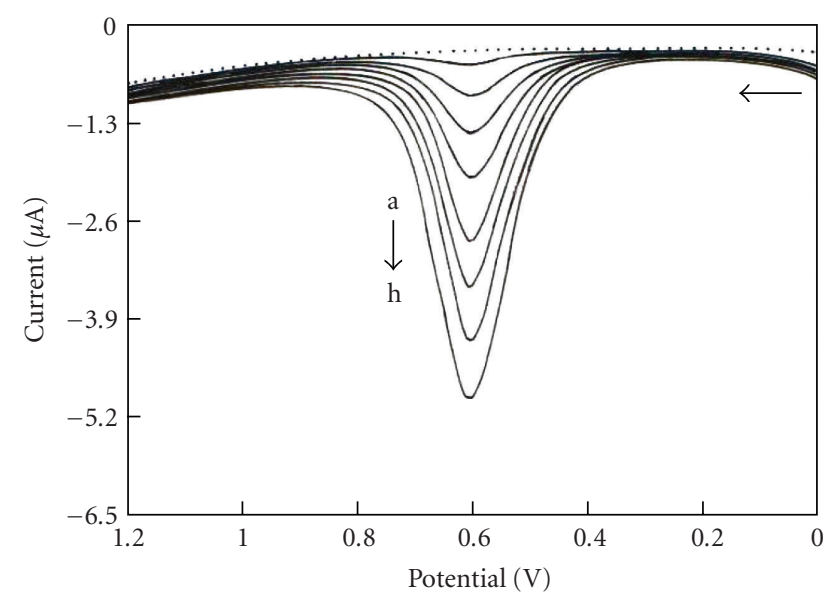

FIGURE 5: Square wave voltammograms of various concentrations of salbutamol at SWNT-modified EPPGE in $1 \mathrm{M}$ phosphate buffer ( $\mathrm{pH} 7.2)$; [salbutamol]: $\mathrm{a}=50, \mathrm{~b}=250, \mathrm{c}=500, \mathrm{~d}=750, \mathrm{e}=$ $1250, \mathrm{f}=1500, \mathrm{~g}=1750, \mathrm{~h}=2000 \mathrm{ng} / \mathrm{mL}$.

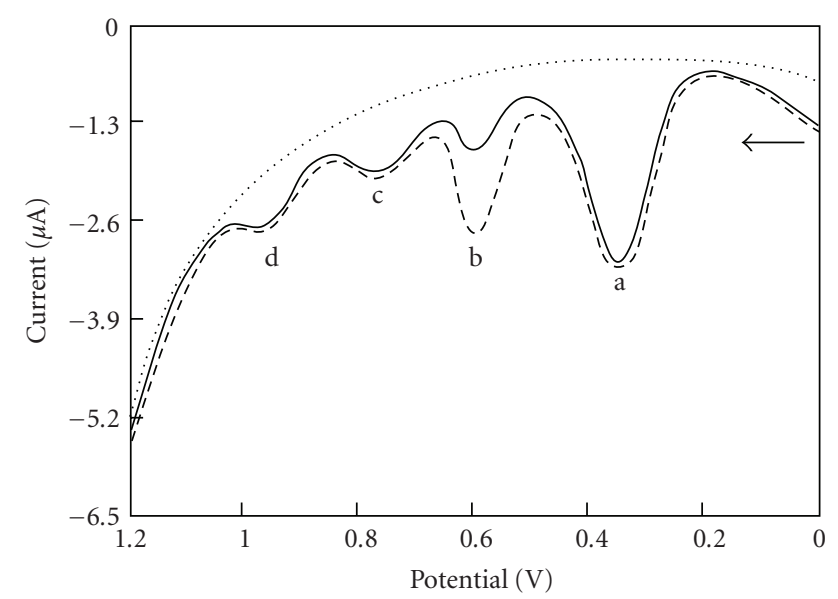

FIGURE 6: Square wave voltammograms for urine sample of asthma patient (-) and urine sample of patient spiked with salbutamol (--) using SWNT/EPPGE. The background PBS at modified electrode is shown as (...).
TABle 1: Determination of salbutamol in different pharmaceutical preparations using SWNT/EPPGE.

\begin{tabular}{lccc}
\hline Tablet & $\begin{array}{c}\text { Amount labeled } \\
(\mathrm{mg})\end{array}$ & $\begin{array}{c}\text { Amount detected } \\
(\mathrm{mg})\end{array}$ & Error \% \\
\hline Salbetol-2 & 2.00 & 2.05 & $+2.5 \%$ \\
Asthalin-2 & 2.00 & 2.04 & $+2.0 \%$ \\
Asthalin-4 & 4.00 & 3.90 & $-2.5 \%$ \\
Ventorlin-8 & 8.00 & 7.99 & $-0.12 \%$ \\
Eto-Salbetol & 2.00 & 1.99 & $-0.5 \%$ \\
\hline
\end{tabular}

${ }^{\mathrm{a}}$ The RSD value for the determination of salbutamol was less than $\pm 2.2 \%$ for $n=3$.

TABLe 2: Recovery data for salbutamol determination in plasma samples of healthy volunteers at SWNT-modified EPPGE.

\begin{tabular}{lcc}
\hline Spiked amount $(\mu \mathrm{M})$ & Detected amount $\mathrm{t}^{\mathrm{a}}(\mu \mathrm{M})$ & Recovery $(\%)$ \\
\hline Sample 1 & & \\
0.50 & 0.50 & 100.00 \\
1.00 & 0.99 & 99.00 \\
1.50 & 1.49 & 99.33 \\
Sample 2 & & \\
0.50 & 0.49 & 98.00 \\
1.00 & 0.98 & 98.00 \\
1.50 & 1.49 & 99.33 \\
\hline
\end{tabular}

${ }^{\mathrm{a}}$ The RSD value for the determination of salbutamol was less than $\pm 3.2 \%$ for $n=3$.

\subsection{Analytical Utility}

3.3.1. Real Sample Analysis. In order to establish the analytical utility of the proposed method, attempts have been made to analyze the urine sample of an asthma patient undergoing treatment with salbutamol for the last 8 months. Urine sample was collected after oral administration of $2 \mathrm{mg}$ salbutamol tablet (Salbetol-2). Prior to analysis, the urine sample was diluted 2 times with $\mathrm{PBS}$ of $\mathrm{pH} 7.2$ in order to minimize interference of matrix. Square wave voltammograms of the urine sample of the patient spiked with known 
TABLE 3: A comparison of voltammetric response of SWNT/EPPGE with previously reported methods for the determination of salbutamol.

\begin{tabular}{|c|c|c|c|c|c|c|}
\hline Sr. no. & Electrode & $\begin{array}{l}\text { Concentration } \\
\text { range }(\mu \mathrm{M})\end{array}$ & $\begin{array}{l}\text { Limit of detection } \\
(\mu \mathrm{M})\end{array}$ & $\begin{array}{l}\text { Sensitivity } \\
(\mu \mathrm{A} / \mu \mathrm{M})\end{array}$ & $\begin{array}{l}\text { Analytical utility } \\
\text { real samples }\end{array}$ & Ref. no. \\
\hline \multirow[t]{2}{*}{ (1) } & Pt electrode & $100-1000$ & 80.00 & 0.012 & No & {$[22]$} \\
\hline & GCE & $20-1000$ & 10.00 & 0.066 & No & {$[22]$} \\
\hline (2) & NGITO & $0.20-8.35$ & 0.31 & 0.055 & Yes & {$[23]$} \\
\hline (3) & GCE & $0.80-80.00$ & 0.20 & - & No & {$[24]$} \\
\hline (4) & MWNT/GCE & $0.80-10.00$ & 0.20 & 0.620 & No & {$[25]$} \\
\hline (5) & $\mathrm{C}_{60} / \mathrm{GCE}$ & $0.42-8.35$ & 0.17 & 0.048 & Yes & {$[26]$} \\
\hline (6) & GN/GCE & 5-90 & 0.10 & - & No & {$[27]$} \\
\hline$(7)$ & SWNT/EPPGE & $0.20-10.45$ & 0.018 & 0.520 & Yes & Proposed method \\
\hline
\end{tabular}

amount of salbutamol were then recorded under optimized parameters using SWNT-modified EPPGE. Figure 6 clearly shows that a well-defined oxidation peak was observed at $\sim 600 \mathrm{mV}$ (peak b) in urine sample of the patient. In order to confirm that this peak is due to the excreted salbutamol in urine, a known amount of authentic salbutamol was spiked in the diluted urine sample of the patient. It was observed that the peak current of peak at $\sim 600 \mathrm{mV}$ increased on spiking of salbutamol, indicating thereby that the peak at $E_{p} \sim 600$ is due to the oxidation of salbutamol excreted in the urine sample of the patient. Some additional peaks were also observed in the urine sample at $\sim 300$ (a), 780 (c), and $\sim 980 \mathrm{mV}$ (d) and were likely to be due to the oxidation of major urinary metabolites, that is, uric acid, xanthine, and hypoxanthine, respectively, although no efforts had been made to analyze them. The concentration of salbutamol in the patient's urine sample was calculated by using calibration plot and found to be $2.00 \mu \mathrm{M}$, which was further confirmed using standard addition method. The RSD for the determination was found to be less than $2.2 \%$ for $n=5$.

3.3.2. Pharmaceutical Analysis. The proposed method was also used to analyze salbutamol-containing tablets to determine their salbutamol content using SWNT-modified EPPGE. The salbutamol content was determined in five common medicinal tablets, that is, Salbetol-2 (Verna industrial estats verna, FDC Ltd., Mfg. Lic no. 656), Asthalin2 (Mfd. by Cipla Ltd.), Asthalin-4 (Mfd. by Cipla Ltd.), Ventorlin-8 (Mfd. by Themis laboratories Pvt. Ltd., Mfg. Lic no. KD-638), and Eto-Salbetol (Mfd. by Kare labs Pvt. Ltd., Mfg. Lic. no. 314). Firstly, tablets were crushed and dissolved in double-distilled water. The solutions obtained by dissolution of tablets were subsequently diluted so that reported salbutamol concentration falls in the range of calibration plot. Square wave voltammograms were then recorded under identical conditions which were used during plotting the calibration plot. The concentration of salbutamol determined by employing the proposed method in different pharmaceutical formulations is compared with labeled concentration of salbutamol and summarized in Table 1. The results show that salbutamol content for all pharmaceutical preparations fall within the claimed amount with error of $\pm 2.5 \%$ indicating the adequate accuracy of the proposed method.
3.4. Recovery Study. In order to examine the stability of salbutamol in human body fluids and the accuracy of the developed method, recovery experiments were carried out at SWNT/EPPGE. Square wave voltammograms of plasma samples from two healthy volunteers were recorded for this purpose. Recovery experiments were carried out by standard addition method using SWNT-modified EPPGE. The drugfree plasma samples were spiked with known concentrations of standard solution of salbutamol followed by recording their voltammograms. The concentration of salbutamol was calculated by using regression equation, and the results observed are tabulated in Table 2 . The recoveries varied in the range from $98.00 \%$ to $100.00 \%$ with relative standard deviation (RSD) of $\pm 3.2 \%$ indicating good accuracy of the proposed sensor, and adequate stability of salbutamol in body fluids is also recommended.

\section{Conclusions}

The results presented in this paper indicated that square wave voltammetry associated with the use of SWNT/EPPGE serves as a fast and reliable tool for the analysis of salbutamol in the biological system. SWNT/EPPGE exhibits improved electrocatalytic properties with enhanced peak current and decreased peak potential as compared to bare EPPGE and several other electrodes. The ability to mediate fast electron transfer reaction with salbutamol in solution makes the modified electrode an ideal candidate for its use in electrochemical experiments. The two important analytical parameters for efficient quantitative determination are sensitivity and detection limit. It was found that the sensitivity of salbutamol determination was almost three times higher using the modified electrode as compared to the bare electrode, and detection limit was also low enough at SWNT/EPPGE. Findings of the proposed work prove that the above-described approach can be a desirable pathway for fabrication of sensors based on nanotubes systems. It was also found that detection limit, sensitivity, and practical utility of the proposed method utilizing SWNT/EPPGE are much better than earlier reported methods (Table 3 ). The detection limit at the proposed electrode is almost ten and sixty times lower than that reported recently at MWNT/GCE and graphite-nanosheet-modified electrodes, respectively $[25,27]$, and sensitivity is ten times higher 
than nanogold-modified ITO [23]. Real sample analysis is an important analytical utility of any sensor; however, no information regarding real sample analysis has been provided in recently reported methods using MWNT/GCE for salbutamol determination. Thus, it is reasonable to conclude that SWNT/EPPGE is a better sensor for the determination of salbutamol in comparison to nanogold-modified ITO or several other conventional electrodes reported earlier (Table 3). The proposed sensor showed a good linear range, low detection limit, good reproducibility, satisfactory recovery results, and high stability making this system a promising example of chemical sensor and interesting alternative for quantification of salbutamol in human body fluids as well as in commercial preparations.

\section{Acknowledgment}

The authors (S. Bishnoi and B. Agarwal) are thankful to the Council of Scientific and Industrial Research, New Delhi for awarding them the Senior Research fellowship and the Junior Research fellowship, respectively.

\section{References}

[1] V. M. Balanag, F. Yunus, P. C. Yang, and C. Jorup, "Efficacy and safety of budesonide/formoterol compared with salbutamol in the treatment of acute asthma," Pulmonary Pharmacology and Therapeutics, vol. 19, no. 2, pp. 139-147, 2006.

[2] R. Ventura, L. Damasceno, M. Farré, J. Cardoso, and J. Segura, "Analytical methodology for the detection of $\beta$ agonists in urine by gas chromatography-mass spectrometry for application in doping control," Analytica Chimica Acta, vol. 418, no. 1, pp. 79-92, 2000.

[3] S. M. Dennis, S. J. Sharp, M. R. Vickers et al., "Regular inhaled salbutamol and asthma control: the TRUST randomised trial," Lancet, vol. 355, no. 9216, pp. 1675-1679, 2000.

[4] M. R. Ganjali, P. Norouzi, M. Ghorbani, and A. Sepehri, "Fourier transform cyclic voltammetric technique for monitoring ultratrace amounts of salbutamol at gold ultra microelectrode in flowing solutions," Talanta, vol. 66, no. 5, pp. 1225-1233, 2005.

[5] B. Valenzuela, A. Nácher, V. G. Casabó, and A. MartínVillodre, "The influence of active secretion processes on intestinal absorption of salbutamol in the rat," European Journal of Pharmaceutics and Biopharmaceutics, vol. 52, no. 1, pp. 31-37, 2001.

[6] I. Dol and M. Knochen, "Flow-injection spectrophotometric determination of salbutamol with 4-aminoantipyrine," Talanta, vol. 64, no. 5, pp. 1233-1236, 2004.

[7] M. Cope and F. Bautista-Parra, "The degradation of salbutamol in ethanolic solutions," Journal of Pharmaceutical and Biomedical Analysis, vol. 52, no. 2, pp. 210-215, 2010.

[8] V. A. Sakkas, P. Calza, C. Medana et al., "Heterogeneous photocatalytic degradation of the pharmaceutical agent salbutamol in aqueous titanium dioxide suspensions," Applied Catalysis B, vol. 77, no. 1-2, pp. 135-144, 2007.

[9] M. Cepero, Y. Pérez-Pertejo, J. C. Cubría et al., "Muscle and serum changes with salbutamol administration in aerobically exercised rats," Comparative Biochemistry and Physiology C, vol. 126, no. 1, pp. 45-51, 2000.
[10] Q. Chen, L.-Y. Fan, W. Zhang, and C.-X. Cao, "Separation and determination of abused drugs clenbuterol and salbutamol from complex extractants in swine feed by capillary zone electrophoresis with simple pretreatment," Talanta, vol. 76, no. 2, pp. 282-287, 2008.

[11] R. Ventura, R. Ramírez, N. Monfort, and J. Segura, "Ultraperformance liquid chromatography tandem mass spectrometric method for direct quantification of salbutamol in urine samples in doping control," Journal of Pharmaceutical and Biomedical Analysis, vol. 50, no. 5, pp. 886-890, 2009.

[12] M.-H. Spyridaki, P. Kiousi, A. Vonaparti et al., "Doping control analysis in human urine by liquid chromatographyelectrospray ionization ion trap mass spectrometry for the Olympic Games Athens 2004: determination of corticosteroids and quantification of ephedrines, salbutamol and morphine," Analytica Chimica Acta, vol. 573-574, pp. 242-249, 2006.

[13] J. Zhang, Y. Xu, X. Di, and M. Wu, "Quantitation of salbutamol in human urine by liquid chromatography- electrospray ionization mass spectrometry," Journal of Chromatography B, vol. 831, no. 1-2, pp. 328-332, 2006.

[14] S. H. R. A. Mazhar and H. Chrystyn, "New HPLC assay for urinary salbutamol concentrations in samples collected postinhalation," Journal of Pharmaceutical and Biomedical Analysis, vol. 50, no. 2, pp. 175-182, 2009.

[15] S. Sirichai and P. Khanatharana, "Rapid analysis of clenbuterol, salbutamol, procaterol, and fenoterol in pharmaceuticals and human urine by capillary electrophoresis," Talanta, vol. 76, no. 5, pp. 1194-1198, 2008.

[16] D. Šatínský, R. Karlíček, and A. Svoboda, "Using on-line solid phase extraction for flow-injection spectrophotometric determination of salbutamol," Analytica Chimica Acta, vol. 455, no. 1, pp. 103-109, 2002.

[17] Y. M. Koh, M. I. Saleh, and S. C. Tan, "Selective extraction of salbutamol from human plasma with the use of phenylboronic acid," Journal of Chromatography A, vol. 987, no. 1-2, pp. 257267, 2003.

[18] Y. M. Issa, A. F. Shoukry, and R. M. El-Nashar, "Conductimetric determination of reproterol $\mathrm{HCl}$ and pipazethate $\mathrm{HCl}$ and salbutamol sulphate in their pharmaceutical formulations," Journal of Pharmaceutical and Biomedical Analysis, vol. 26, no. 3, pp. 379-386, 2001.

[19] C. A. Lindino and L. O. S. Bulhões, "Determination of fenoterol and salbutamol in pharmaceutical formulations by electrogenerated chemiluminescence," Talanta, vol. 72, no. 5, pp. 1746-1751, 2007.

[20] V. Pedrosa, S. Machado, and L. Avaca, "Application of a deconvolutive procedure to analyze several chlorophenol species in natural waters by square-wave voltammetry on the boron-doped diamond electrode," Analytical Letters, vol. 39, no. 9, pp. 1955-1965, 2006.

[21] R. N. Goyal and S. Bishnoi, "Simultaneous voltammetric determination of prednisone and prednisolone in human body fluids," Talanta, vol. 79, no. 3, pp. 768-774, 2009.

[22] N. Yilmaz, S. A. Özkan, B. Uslu, Z. Şentürk, and I. Biryol, "Voltammetric determination of salbutamol based on electrochemical oxidation at platinum and glassy carbon electrodes," Turkish Journal of Chemistry, vol. 22, no. 2, pp. 175-182, 1998.

[23] R. N. Goyal, M. Oyama, and S. P. Singh, "Fast determination of salbutamol, abused by athletes for doping, in pharmaceuticals and human biological fluids by square wave voltammetry," Journal of Electroanalytical Chemistry, vol. 611, no. 1-2, pp. 140-148, 2007. 
[24] K. A. Sagar, M. R. Smyth, and R. Munden, "Voltammetric study of salbutamol and application to its determination in a tablet dosage form and dissolution profiles for the dosage form," Journal of Pharmaceutical and Biomedical Analysis, vol. 11, no. 7, pp. 533-540, 1993.

[25] Y. Wei, Q. Zhang, C. Shao, C. Li, L. Zhang, and X. Li, "Voltammetric determination of salbutamol on a glassy carbon electrode coated with a nanomaterial thin film," Journal of Analytical Chemistry, vol. 65, no. 4, pp. 398-403, 2010.

[26] R. N. Goyal, D. Kaur, S. P. Singh, and A. K. Pandey, "Effect of graphite and metallic impurities of C fullerene on determination of salbutamol in biological fluids," Talanta, vol. 75, no. 1, pp. 63-69, 2008.

[27] LI. Shen, Z. Li, and P. He, "Electrochemical behavior of $\beta$ agonists at graphite nanosheet modified electrodes," Electrochemistry Communications, vol. 12, pp. 876-881, 2010.

[28] R. N. Goyal, A. Aliumar, and M. Oyama, "Comparison of spherical nanogold particles and nanogold plates for the oxidation of dopamine and ascorbic acid," Journal of Electroanalytical Chemistry, vol. 631, no. 1-2, pp. 58-61, 2009.

[29] D. S. Shishmarev, N. V. Rees, and R. G. Compton, "Full paper enhanced performance of edge-plane pyrolytic graphite (EPPG) electrodes over glassy carbon (GC) electrodes in the presence of surfactants: application to the stripping voltammetry of copper," Electroanalysis, vol. 22, no. 1, pp. 3134, 2010.

[30] R. T. Kachoosangi and R. G. Compton, "A simple electroanalytical methodology for the simultaneous determination of dopamine, serotonin and ascorbic acid using an unmodified edge plane pyrolytic graphite electrode," Analytical and Bioanalytical Chemistry, vol. 387, no. 8, pp. 2793-2800, 2007.

[31] W. Yue-Rong, H. Ping, L. Qiong-Lin, L. Guo, and W. YiMing, "Application of carbon nanotube modified electrode in bioelectroanalysis," Chinese Journal of Analytical Chemistry, vol. 36, no. 8, pp. 1011-1016, 2008.

[32] F. Valentini, S. Orlanducci, M. L. Terranova, A. Amine, and G. Palleschi, "Carbon nanotubes as electrode materials for the assembling of new electrochemical biosensors," Sensors and Actuators B, vol. 100, no. 1-2, pp. 117-125, 2004.

[33] R. Antiochia and L. Gorton, "Development of a carbon nanotube paste electrode osmium polymer-mediated biosensor for determination of glucose in alcoholic beverages," Biosensors and Bioelectronics, vol. 22, no. 11, pp. 2611-2617, 2007.

[34] A. Curulli, F. Valentini, G. Padeletti, M. Viticoli, D. Caschera, and G. Palleschi, "Smart (Nano) materials: TiO nanostructured films to modify electrodes for assembling of new electrochemical probes," Sensors and Actuators B, vol. 111-112, pp. 441-449, 2005.

[35] A. Merkoçi, M. Pumera, X. Llopis, B. Pérez, M. Del Valle, and S. Alegret, "New materials for electrochemical sensing VI: carbon nanotubes," Trends in Analytical Chemistry, vol. 24, no. 9, pp. 826-838, 2005.

[36] D. Abd El-Hady, M. I. Abdel-Hamid, M. M. Seliem, V. Andrisano, and N. Abo El-Maali, "Osteryoung square wave stripping voltammetry at mercury film electrode for monitoring ultra trace levels of Tarabine PFS and its interaction with ssDNA," Journal of Pharmaceutical and Biomedical Analysis, vol. 34, no. 5, pp. 879-890, 2004.

[37] R. A. De Toledo, M. Castilho, and L. H. Mazo, "Determination of dipyridamole in pharmaceutical preparations using square wave voltammetry," Journal of Pharmaceutical and Biomedical Analysis, vol. 36, no. 5, pp. 1113-1117, 2005.
[38] R. N. Goyal, M. Oyama, and A. Tyagi, "Fullerene- $\mathrm{C}_{60}$ modified edge plane pyrolytic graphite electrode for the determination of dexamethasone in pharmaceutical formulations and human biological fluids," Biosensors and Bioelectronics, vol. 581, pp. 32-36, 2007.

[39] G. D. Christian and W. C. Purdy, "The residual current in orthophosphate medium," Journal of Electroanalytical Chemistry, vol. 3, no. 6, pp. 363-373, 1962.

[40] C. E. Banks, M. R. Moore, T. J. Davies, and R. G. Compton, "Investigation of modified basal plane pyrolytic graphite electrodes: definitive evidence for the electrocatalytic properties of the ends of carbon nanotubes," Chemical Communications, vol. 10, no. 16, pp. 1804-1805, 2004.

[41] X. Liu, V. Gurel, D. Morris et al., "Bioavailability of nickel in single-wall carbon nanotubes," Advanced Materials, vol. 19, no. 19, pp. 2790-2796, 2007.

[42] R. H. Wopschall and I. Shain, "Adsorption characteristics of the methylene blue system using stationary electrode polarography," Analytical Chemistry, vol. 39, no. 13, pp. 15271534, 1967.

[43] F. Quente and C. Elleouet, "Square-wave voltammetry of molybdenum-fulvic acid complex," Electroanalysis, vol. 13, no. 12, pp. 1030-1035, 2001.

[44] X. Jiang and X. Lin, "Overoxidized polypyrrole film directed DNA immobilization for construction of electrochemical micro-biosensors and simultaneous determination of serotonin and dopamine," Analytica Chimica Acta, vol. 537, no. 1-2, pp. 145-151, 2005. 


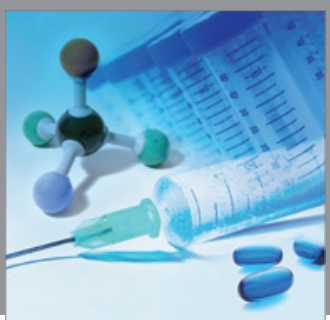

International Journal of

Medicinal Chemistry

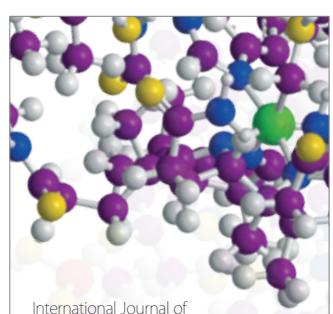

Carbohydrate Chemistry

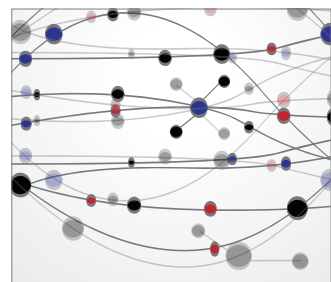

The Scientific World Journal
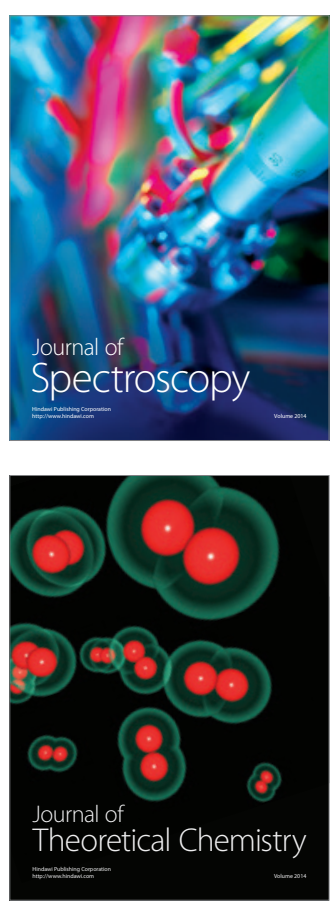
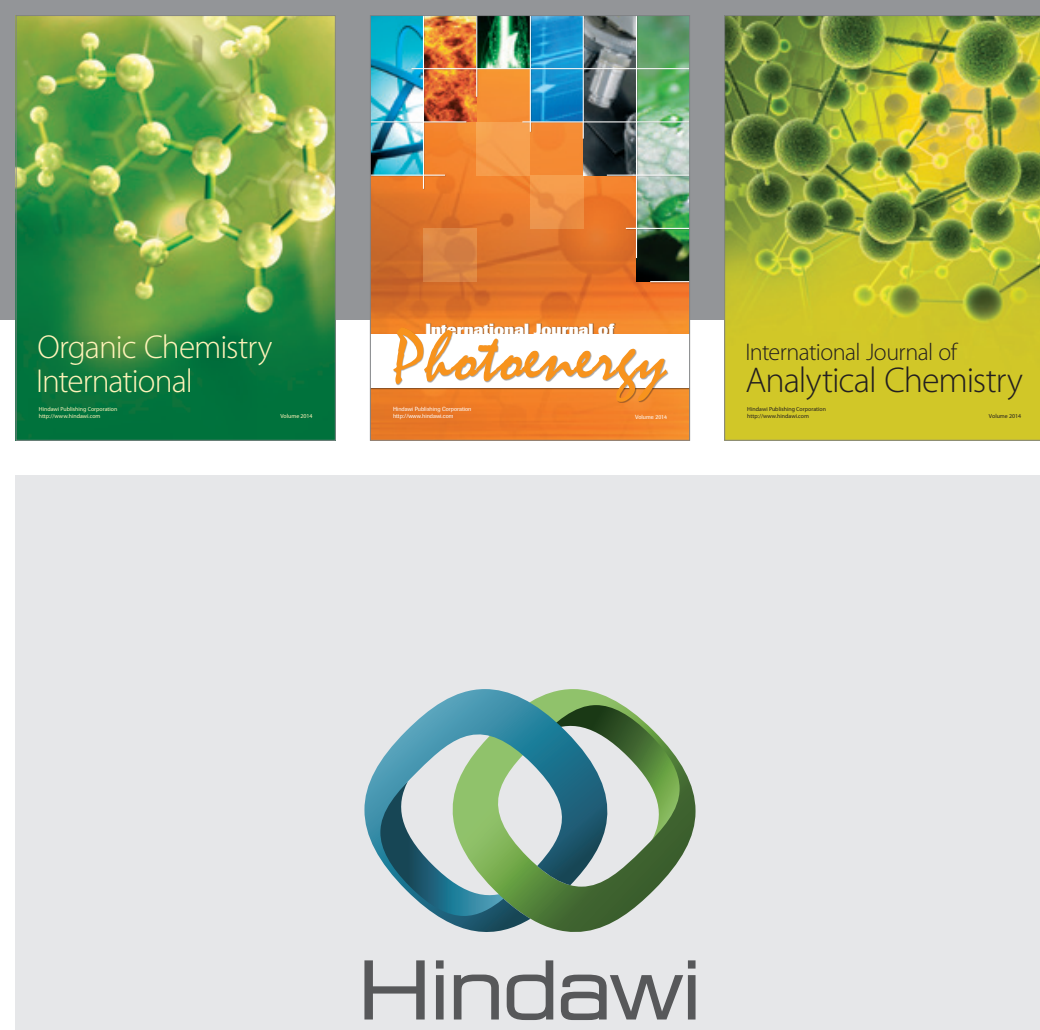

Submit your manuscripts at

http://www.hindawi.com
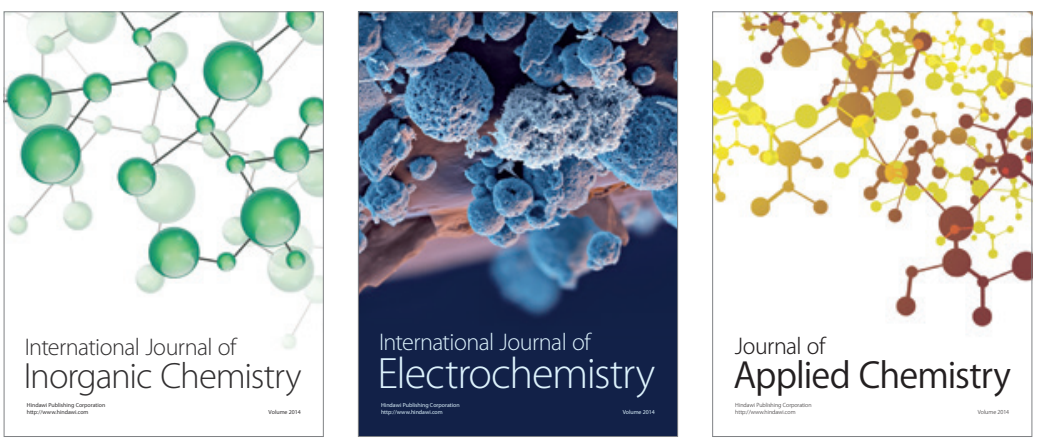

Journal of

Applied Chemistry
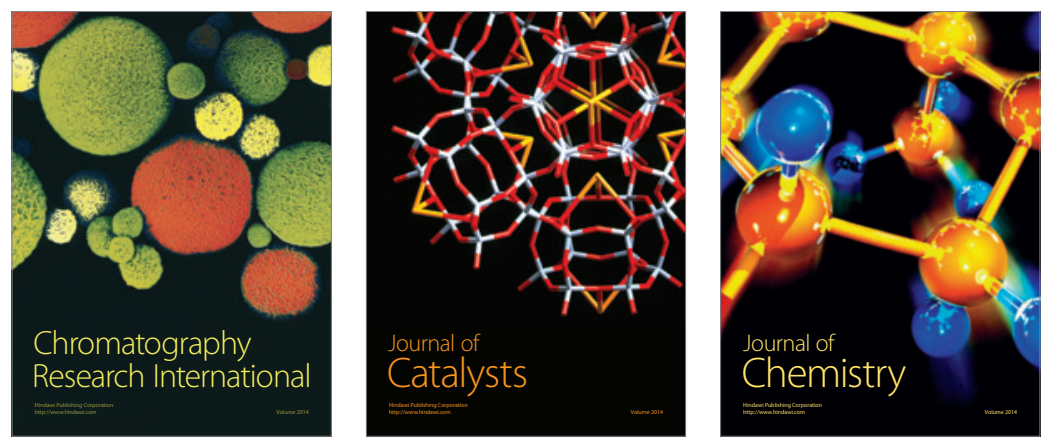
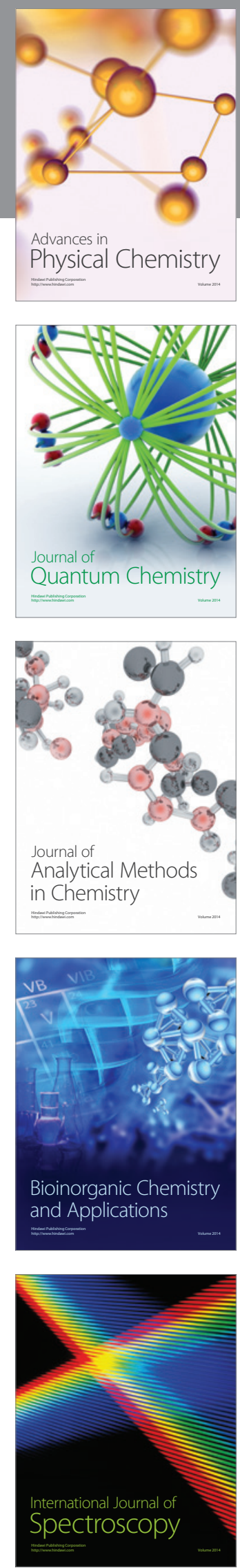